\title{
Article \\ Solid Solution Strengthening of Mo, Re, Ta and W in Ni during High-Temperature Creep
}

\author{
Lukas Haußmann *, Hamad ur Rehman, Dorothea Matschkal, Mathias Göken and Steffen Neumeier *D
}

Citation: Haußmann, L.;

ur Rehman, H.; Matschkal, D.;

Göken, M.; Neumeier, S. Solid

Solution Strengthening of Mo, Re, Ta and $\mathrm{W}$ in Ni during High-

Temperature Creep. Metals 2021, 11,

1909. https://doi.org/10.3390/

met11121909

Academic Editor: Elisabetta Gariboldi

Received: 27 October 2021

Accepted: 22 November 2021

Published: 26 November 2021

Publisher's Note: MDPI stays neutral with regard to jurisdictional claims in published maps and institutional affiliations.

Copyright: (c) 2021 by the authors. Licensee MDPI, Basel, Switzerland. This article is an open access article distributed under the terms and conditions of the Creative Commons Attribution (CC BY) license (https:// creativecommons.org/licenses/by/ $4.0 /)$.
Department of Materials Science \& Engineering, Institute I: General Materials Properties, Friedrich-Alexander-Universität Erlangen-Nürnberg, 91058 Erlangen, Germany; Hamadur.Rehman@boschrexroth.de (H.u.R.); Dorothea.Amberger@fau.de (D.M.); Mathias.Goeken@fau.de (M.G.)

* Correspondence: Lukas.Haussmann@fau.de (L.H.); Steffen.Neumeier@fau.de (S.N.)

\begin{abstract}
Solid solution strengthening of the unordered $\gamma$ matrix phase by alloying elements is of great importance during creep of Ni-based superalloys, particularly at high temperatures above $1000^{\circ} \mathrm{C}$. To study the role of different potent solutes, we have conducted creep experiments on binary Ni-2X alloys $(\mathrm{X}=\mathrm{Mo}, \mathrm{Re}, \mathrm{Ta}, \mathrm{W})$ at $1000{ }^{\circ} \mathrm{C}, 1050{ }^{\circ} \mathrm{C}$, and $1100{ }^{\circ} \mathrm{C}$ at a constant stress of $20 \mathrm{MPa}$. Compared to mechanical tests below $800{ }^{\circ} \mathrm{C}$, where the size of the elements mostly determines the solid solution hardening contribution, the strengthening contribution of the different alloying elements above $1000{ }^{\circ} \mathrm{C}$ directly correlates with their diffusivity. Therefore, elements such as Ta that lead to strong solid solution hardening at low temperatures become less effective at higher temperatures and are exceeded by slower diffusing elements, such as Re.
\end{abstract}

Keywords: nickel; diffusion; solid solution hardening; creep

\section{Introduction}

The economically and ecologically fueled demand for more efficiency requires steadily increasing operating temperatures in gas turbines and aero-engines. To fulfill these demands on high-temperature resistant Ni-based superalloys used in the hottest parts of these energy conversion systems, the used materials have to be constantly improved. With increasing temperatures, diffusion-controlled processes begin to gain considerable influence on the mechanical properties of Ni-based superalloys under creep load [1-6]. Especially in a high-temperature and low-stress creep regime, slow diffusing refractory elements such as Re, W, and Mo are used to increase creep strength [4,7-14]. However, at lower temperatures other elements such as Ta exhibit higher strengthening contributions than those slow diffusing elements due to more pronounced solid solution hardening effects [3,15-17].

The theory on strengthening in diluted solid solutions was already described by Fleischer [18] and enhanced by Labusch [19], which correlates the concentration of a solute with the resulting strength increase through a solid solution hardening coefficient. Mishima et al. [15] have investigated the solid solution hardening of different transition metals in Ni, including W, Mo, and Ta. From the data, Roth et al. [20] have determined the solid solution hardening coefficients of $\mathrm{W}$, Mo, and Ta to $1.5 \mathrm{GPa} /$ at. $\%{ }^{2 / 3}$, $1.6 \mathrm{GPa} /$ at. $\%{ }^{2 / 3}$, and $1.8 \mathrm{GPa} /$ at. $\%{ }^{2 / 3}$. Furthermore, the solid solution hardening coefficient for Re was interpolated with the data from [15] to $1.5 \mathrm{GPa} /$ at. $\%{ }^{2 / 3}$ [21]. However, as these solid solution hardening coefficients were determined at $77 \mathrm{~K}$, where the solutes can be assumed to be static objects, the hardening potential of these solutes in Ni should be lower at higher temperatures where the mobility of the solutes is higher [22,23]. This was already observed by Fleischmann et al. [7], who investigated the solid solution hardening potential of Re, W, and Mo in single-phase, single-crystalline Ni-alloys consisting of the unordered $\gamma$ phase. They showed that Re has a $60 \%$ higher solid solution hardening efficiency than $\mathrm{W}$ and Mo at $980{ }^{\circ} \mathrm{C}$ in $\gamma / \gamma^{\prime}$ two-phase, Ni-based superalloys, which 
is largely due to a significantly lower diffusion coefficient and does not correspond to the aforementioned solid solution coefficients [24,25]. Rettig et al. [26] have further clarified the efficacy of Re, $\mathrm{W}$, and Mo as solid solution hardening elements at $980{ }^{\circ} \mathrm{C}$ by deriving an equation for only the $\gamma$ matrix from the data of [7]. In this equation, the efficacy of Re is 2.44 times higher and the efficacy of $W$ is 1.22 times higher than that of Mo.

Giese et al. [27] have also connected the creep strength to the diffusivity of solution hardening elements in creep experiments at $1100^{\circ} \mathrm{C}$ of experimental Ni-base superalloys of the Astra2 series with different solid solution hardening elements. A quite similar approach to that of Giese et al. [27] was chosen by Ru et al. [12], who found a direct relationship between the creep rupture life of Ni-based superalloys with different contents of Re and Mo to the inverse diffusion coefficient.

However, as the creep strength is influenced with increasing temperature by the solid solution hardening effect as well as the diffusivity of the alloying element, the assessment of the hardening capability of solutes in Ni-based superalloys is still largely empirical. This was studied broadly by ur Rehman et al. [3] for the solutes Re, Ta, and W in Ni single crystals by strain rate jump tests from $800^{\circ} \mathrm{C}$ to $1200{ }^{\circ} \mathrm{C}$ at strain rates between $10^{-3}$ and $10^{-5}$. They confirmed that if the strain rate is low enough and the temperature is high enough, the solute Re leads to a higher solid solution hardening contribution than Ta. However, in [3] the frequently used solid solution hardening alloying element Mo was not considered. Furthermore, the solid solution behavior of the solutes in $\mathrm{Ni}$ at lower strain rates, where the influence of the diffusion should be more pronounced, was also not considered.

To contribute to the clarification of the correlation between diffusivity and solid solution hardening of solutes in $\mathrm{Ni}$, the influence of the solutes Mo, Re, Ta, and $\mathrm{W}$ on the creep behavior of $\mathrm{Ni}$ has been investigated by creep experiments on binary Ni-alloys with a $20 \mathrm{MPa}$ creep load between $1000{ }^{\circ} \mathrm{C}$ and $1100{ }^{\circ} \mathrm{C}$. The aim was to study whether there is a direct correlation between the diffusion coefficient of the solute and the resulting creep strength.

\section{Materials and Methods}

The binary alloys Ni-2Ta, Ni-2W, and Ni-2Re (at.\%) were cast in an industrial scale investment casting facility (Birmingham, UK) to single crystalline rods in $\langle 100\rangle$ direction. The diameter of the cast rods was $15 \mathrm{~mm}$ and the length was $150 \mathrm{~mm}$. Further details about this casting process can be found elsewhere [28]. The alloy $\mathrm{Ni}-2 \mathrm{Mo}$ (at.\%) was cast at $1560{ }^{\circ} \mathrm{C}$ in the Bridgeman process using a withdrawal speed of $3 \mathrm{~mm} / \mathrm{min}$ to single crystalline rods in $\langle 100\rangle$ direction, with a diameter of $12 \mathrm{~mm}$ and a length of $95 \mathrm{~mm}$. After casting, all rods were macro etched to ensure there were no casting defects. With the solute concentration of 2 at.\%, complete solubility could be ensured for all alloys and testing temperatures.

Creep specimens were manufactured by electric discharge machining with a diameter of $5 \mathrm{~mm}$ and a height of $7.5 \mathrm{~mm}$. The specimens were subsequently ground plane parallel to an accuracy better than $10 \mu \mathrm{m}$. The creep experiments were conducted at temperatures of $1000{ }^{\circ} \mathrm{C}, 1050{ }^{\circ} \mathrm{C}$, and $1100{ }^{\circ} \mathrm{C}$, and at a compressive load of $20 \mathrm{MPa}$ using a custombuilt, pneumatic compression creep testing machine. Two S-type thermocouples mounted on the sample were used to ensure an accurate measurement and control of the sample temperature. As the investigated Ni-based alloys were susceptible to oxidation at high temperatures, the external surfaces of the creep specimen were coated with sodium water glass $\left(\mathrm{Na}_{2} \mathrm{SiO}_{3}\right)$. The creep specimen was heated to testing temperature with a pre-load of $20 \mathrm{~N}(\sim 1 \mathrm{MPa})$ and a hold time of $0.5 \mathrm{~h}$ at $600{ }^{\circ} \mathrm{C}$ to improve the formation of a thin viscous layer of sodium water glass. Before applying the creep load at testing temperature, the creep samples were again held for $0.5 \mathrm{~h}$ to ensure thermal stability. 


\section{Results}

The creep curves of single crystalline pure $\mathrm{Ni}$ and binary $\mathrm{Ni}-2 \mathrm{X}$ alloys $(\mathrm{X}=\mathrm{Ta}, \mathrm{W}, \mathrm{Re}$, Mo) are illustrated in Figure 1 for the temperatures of $1000^{\circ} \mathrm{C}, 1050{ }^{\circ} \mathrm{C}$, and $1100{ }^{\circ} \mathrm{C}$. The strain rate over the plastic strain (Figure $1 \mathrm{a}, \mathrm{c}, \mathrm{e}$ ), as well as the corresponding plastic strain over time (Figure 1b,d,f), is shown. As expected, all alloying elements led to an increased creep strength compared to pure Ni. Ni-2Re revealed the highest creep strength of all four alloys at all investigated temperatures. Ni-2W showed the second highest creep strength of the investigated binary alloys, but with an increased difference in creep strength with increased temperature compared to Ni-2Re. Ni-2Mo and Ni-2Ta show quite similar creep strengths at all temperatures. However, at $1000{ }^{\circ} \mathrm{C}$ Ni-2Mo exhibits a slightly higher creep strength than Ni-2Ta.

Furthermore, pure Ni shows a very high primary creep regime, which is clearly noticeable in the strain's rate-strain and strain-time curves. As reported in a previous study [3], the yield stress of $\mathrm{Ni}$ at $1000{ }^{\circ} \mathrm{C}$ is lower than $20 \mathrm{MPa}$, whereas the yield strength of Ni-2Ta, Ni-2W, and Ni-2Re is higher than $20 \mathrm{MPa}$. This explains the very high initial strain rate of pure $\mathrm{Ni}$ at $1000^{\circ} \mathrm{C}, 1050{ }^{\circ} \mathrm{C}$, and $1100^{\circ} \mathrm{C}$. Due to the lower yield strength of pure $\mathrm{Ni}$, a significant amount of plastic deformation at relatively high strain rates took place at the beginning of the creep experiment until a certain dislocation density was formed. Then, the strain rate decreased until a steady state of dislocation generation and dislocation annihilation was reached.

In most cases, a steady state creep rate could be observed during the creep tests. In experiments with a longer experiment duration, a continuous decrease in creep rate could be noticed. This is particularly evident for the Ni-2Re alloy creep at $1050{ }^{\circ} \mathrm{C}$. This indicates that oxidation had a considerable influence at these high temperatures at longer experiment durations, despite the coating with sodium water glass $\left(\mathrm{Na}_{2} \mathrm{SiO}_{3}\right)$. It seems that the protective layer loses its function after some time at very high temperatures and then the creep rate decreases. The increase in creep strength could be due to the increase in the cross section or a supportive effect of the oxide layer.

A steady state strain rate for each alloy at the three testing temperatures could not be determined. Therefore, the creep strain at $2 \%$ plastic strain was used for further evaluation of creep properties for the Ni solid solutions, as the oxidative influence should be negligible at these lower strains. Since the strain rate reached a plateau and did not show large variations before decreasing due to oxidation, the strain rate at $2 \%$ plastic strain should not differ greatly from the steady state creep rate. Due to the pronounced plastic deformation in the beginning of the creep experiments of pure $\mathrm{Ni}$, the strain rate at $13 \%$ plastic strain of $\mathrm{Ni}$ was taken as a quasi-steady state creep rate. The strain rate at $2 \%$ plastic strain of the single crystalline $\mathrm{Ni}-2 \mathrm{X}$ alloys $(\mathrm{X}=\mathrm{Ta}, \mathrm{W}, \mathrm{Re}$, $\mathrm{Mo}$ ) and the strain rate at $13 \%$ plastic strain for pure $\mathrm{Ni}$ is shown in Figure 2 for the different testing temperatures.

Similarly to Figure 1, Ni-2Re shows the highest creep strength, followed by Ni-2W, $\mathrm{Ni}-2 \mathrm{Mo}$, and Ni-2Ta with similar creep strengths. As expected, pure Ni shows the lowest creep strength. The strain rate of Ni-2Re is about one order of magnitude lower than that of Ni-2Ta. Due to the double logarithmic plot, the data of each alloy can be linearly fitted, which shows an exponential correlation between the temperature and the quasi-steady state creep rates. The slope of the linear fit lines of the different binary alloys and pure $\mathrm{Ni}$ differ slightly from each other in some cases. However, this could be due to the lack of a steady state creep rate in some experiments as a result of oxidation.

The creep experiments were conducted at high temperatures above $1000{ }^{\circ} \mathrm{C}\left(\sim 0.7 \mathrm{~T}_{\mathrm{m}}\right)$ where the influence of diffusion-controlled processes is decisive. Additionally, as the stress was quite low, the dislocation motion during creep deformation in solid solutions was carried by thermally assisted processes such as diffusion-controlled climb [29,30]. 


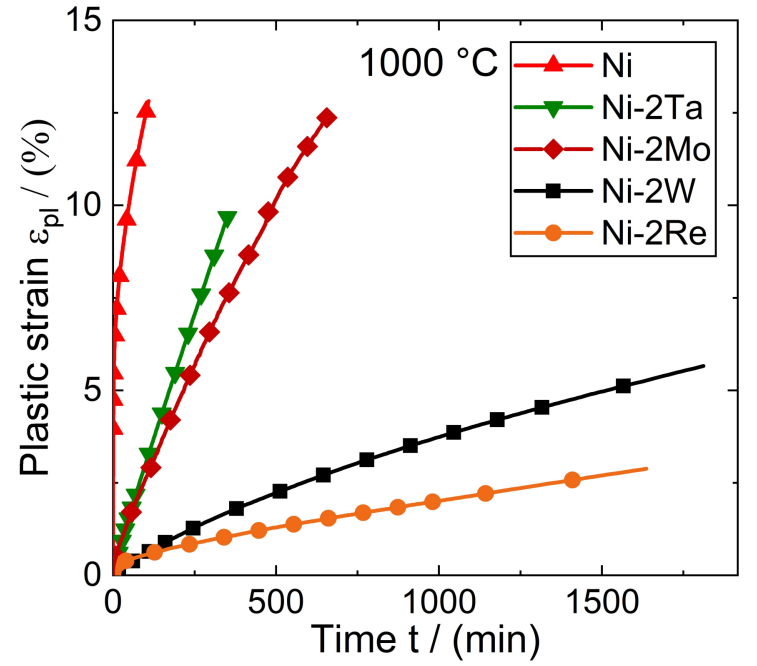

(a)

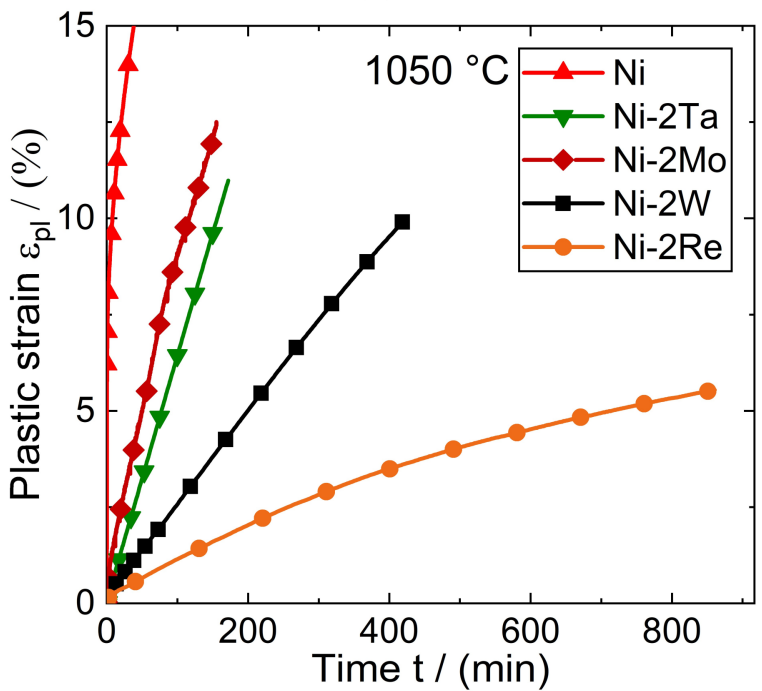

(c)

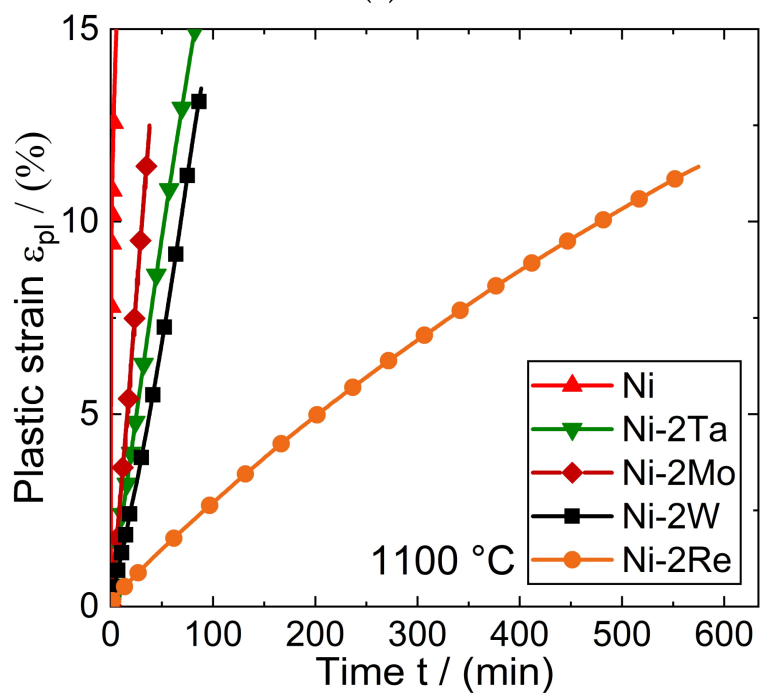

(e)

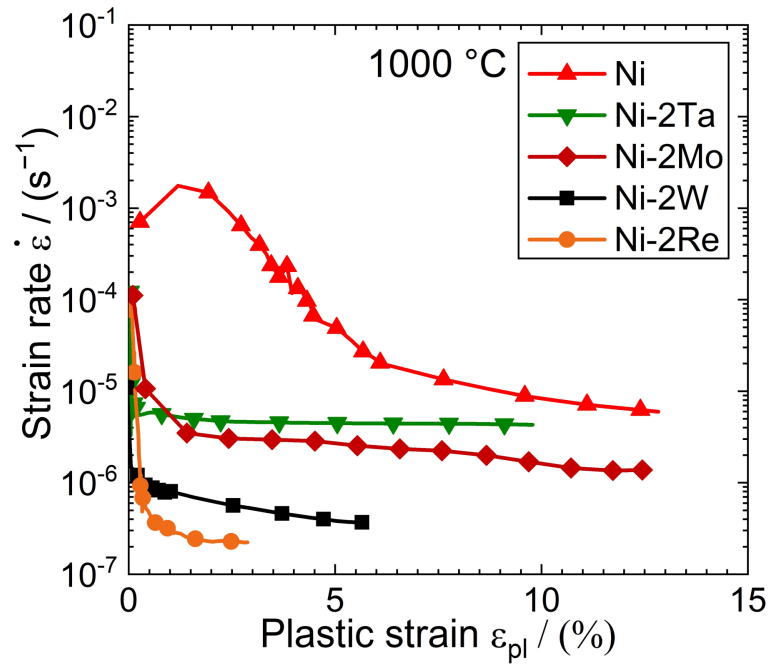

(b)

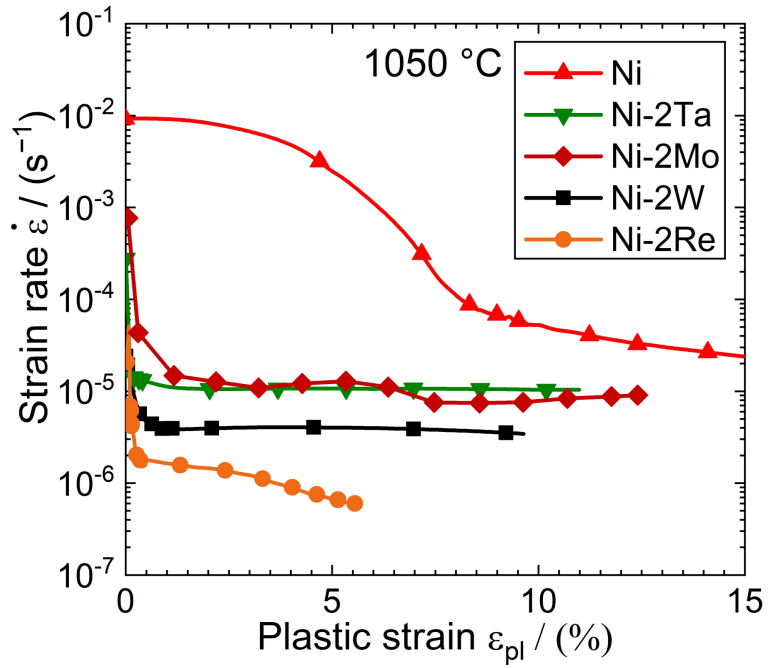

(d)

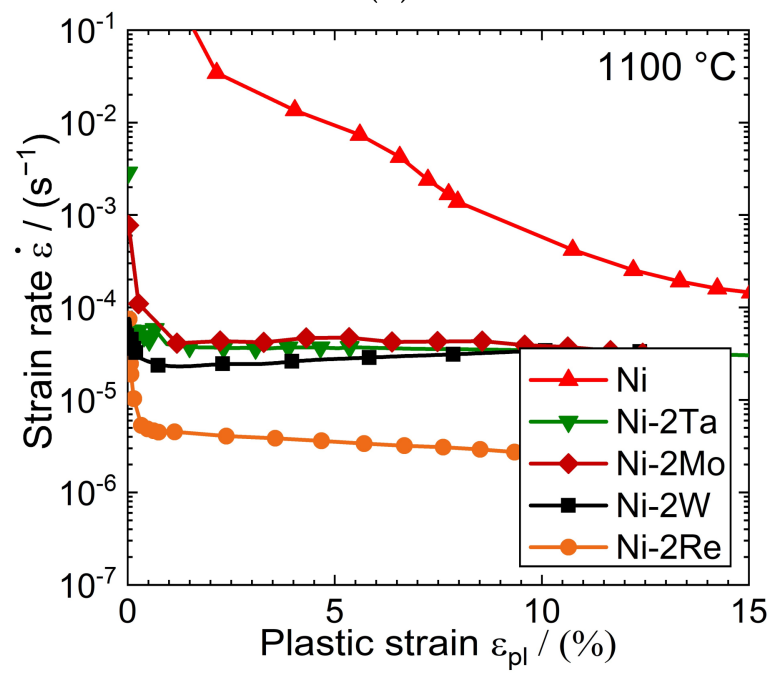

(f)

Figure 1. Plastic strain plotted over time and corresponding strain rate plotted over plastic strain of pure $\mathrm{Ni}$ and the $\mathrm{Ni}-2 \mathrm{X}$ alloys $(\mathrm{X}=\mathrm{Ta}, \mathrm{W}, \mathrm{Re}, \mathrm{Mo})$ at $(\mathbf{a}, \mathbf{b}) 1000^{\circ} \mathrm{C},(\mathbf{c}, \mathbf{d}) 1050{ }^{\circ} \mathrm{C}$, and $(\mathbf{e}, \mathbf{f}) 1100{ }^{\circ} \mathrm{C}$. 


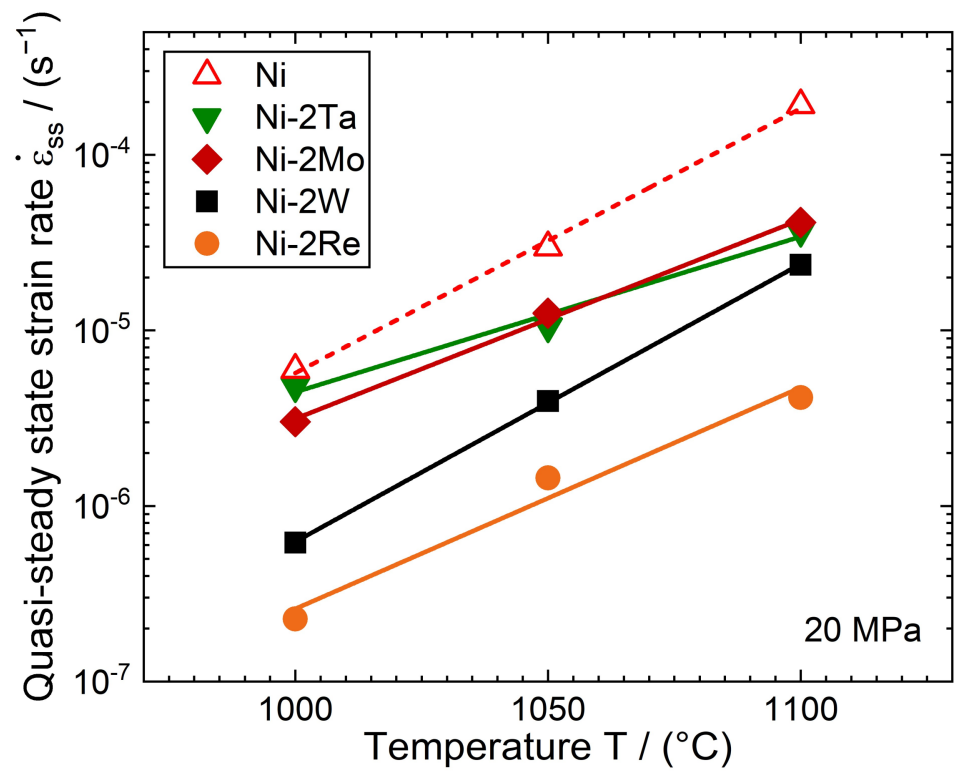

Figure 2. Quasi-steady state strain rates of pure Ni and the Ni-2X ( $\mathrm{X}=\mathrm{Ta}, \mathrm{Mo}, \mathrm{W}, \mathrm{Re})$ plotted over the testing temperature of the creep experiments. For the quasi-steady state strain rates, the strain rate at $13 \%$ plastic strain was used for pure Ni. For Ni-2X (X= Ta, Mo, W, Re), the strain rate at $2 \%$ plastic strain was used.

Furthermore, due to the increased diffusional mobility of the solutes, they can no longer be assumed as immobile obstacles [22,23]. This leads to changes in the solute dislocation interactions. With increasing temperature and diffusion, the solutes can form Cottrell atmospheres in the stress field of the dislocations. Depending on the diffusion and dislocation velocity, the Cottrell clouds can be dragged with the dislocations and slow down the dislocation movement [22,23].

However, as the deformation at high temperatures strongly depends on diffusional processes, the strain rate at $2 \%$ plastic strain was plotted over the solute diffusion coefficient for Ta, W, and Re from [24] and that for Mo from [25], as shown in Figure 3.

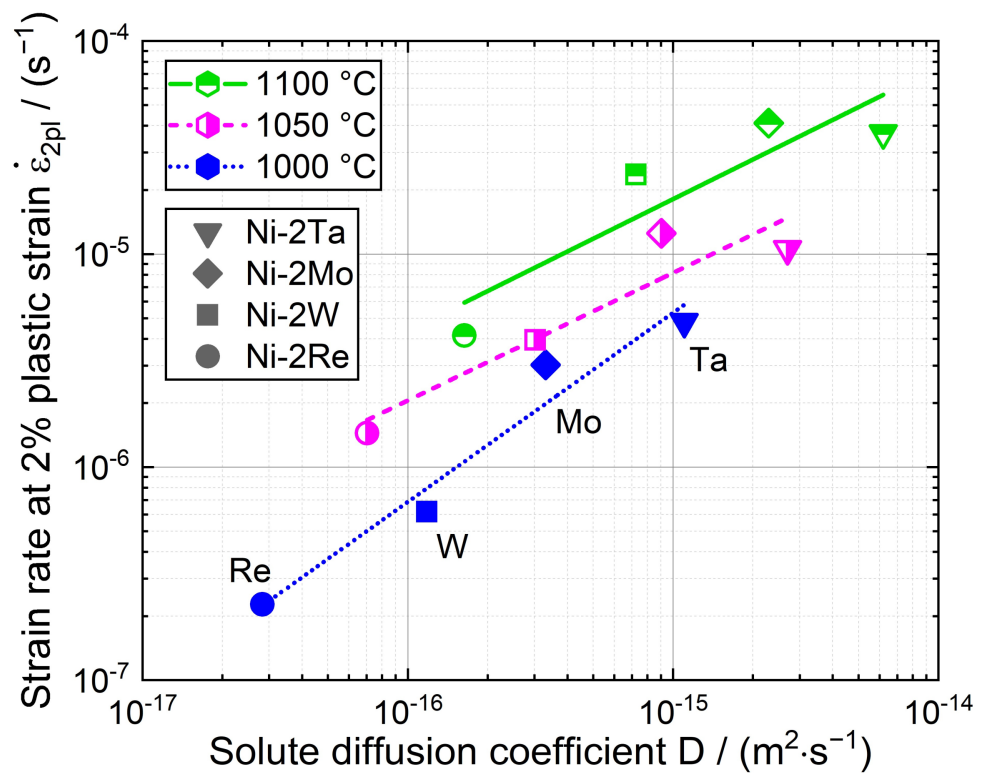

Figure 3. Strain rate at $2 \%$ plastic strain from the creep experiments plotted over the interdiffusion coefficients of Ta, Mo, W, and Re in Ni. The diffusion coefficients of Ta, W, and Re were taken from [24] and that of Mo from [25]. 


\section{Discussion}

The direct dependency of the strain rate on the solute diffusion coefficient in $\mathrm{Ni}$ indicates that the diffusivity of the respective alloying element governs the dislocation mobility and thus the creep rate. Therefore, slower diffusing solutes, such as Re and W, lead to a significantly higher creep strength at low stresses and high temperatures than larger solutes such as $\mathrm{Ta}$, which are potent solid solution hardeners at lower temperatures, but diffuse much faster at higher temperatures.

Giese et al. [27] reported a similar linear behavior in creep experiments at $1100{ }^{\circ} \mathrm{C}$ of experimental Ni-base superalloys of the Astra2 series with different solid solution hardening elements. There, a correlation between the minimum creep rate and a calculated effective diffusion coefficient could be revealed. The Astra2 series consists of multiple alloying elements including $\gamma^{\prime}$ precipitate formers such as $\mathrm{Al}$ and $\mathrm{Ta}$, resulting in a two phase $\gamma / \gamma^{\prime}$-microstructure. Nevertheless, at the very high temperature of $1100{ }^{\circ} \mathrm{C}$, the minimum creep rates of the Astra2 alloys are directly correlated to the diffusion properties and are quite well in line with our findings. Ru et al. [12] have also reported such a linear relationship between the creep properties and the diffusivity in creep experiments at $980^{\circ} \mathrm{C}$ and $1100^{\circ} \mathrm{C}$ on three quinary Ni-Al-Ta-Mo-Re superalloys with a systematically decreasing Re to Mo ratio. This linear relationship could be shown in the plot of the creep rupture life over the inverse effective diffusion coefficient of the respective alloy. Due to the lower diffusivity of Re compared to Mo, the effective diffusion coefficient decreases with increasing Re content and leads to an increased creep rupture life. This underlines that the solid solution hardening capacity of solute elements in Ni in the high-temperature low-stress creep regime strongly depends on the diffusion behavior rather than on the solute size.

In [3], the solid solution hardening behavior of Re, Ta, and $\mathrm{W}$ in Ni between $800{ }^{\circ} \mathrm{C}$ and $1200{ }^{\circ} \mathrm{C}$ was broadly investigated via strain rate jump tests between $10^{-3} \mathrm{~s}^{-1}$ and $10^{-5} \mathrm{~s}^{-1}$. However, while in the present study the creep strength at $1000^{\circ} \mathrm{C}$ is proportional to the diffusion coefficient, the strain rate jump tests in [3] Ni-2Ta shows nearly the same strength as $\mathrm{Ni}-2 \mathrm{~W}$ at $1000^{\circ} \mathrm{C}$. This can be explained by the significantly higher deformation rate in the strain rate jump tests. While the creep experiments at $1000^{\circ} \mathrm{C}$ led to quasi-steady state creep rates between $2 \cdot 10^{-7} \mathrm{~s}^{-1}$ and $5 \cdot 10^{-6} \mathrm{~s}^{-1}$, the deformation rate in the strain rate jump tests is quite higher with $10^{-5} \mathrm{~s}^{-1}$. At an applied strain rate of $10^{-4} \mathrm{~s}^{-1}$ at $1000^{\circ} \mathrm{C}$, $\mathrm{Ni}-2 \mathrm{Ta}$ even exhibits the highest strength compared to Ni-2Re and Ni-2W. At $1100{ }^{\circ} \mathrm{C}$ and an applied strain rate of $10^{-4} \mathrm{~s}^{-1}, \mathrm{Ni}-2 \mathrm{Ta}$ still has a higher strength than Ni-2W.

This shows that besides the application temperature, the deformation rate is heavily important for the evaluation of the solid solution hardening potential of a solute, considering time-dependent processes such as diffusion.

\section{Conclusions}

Binary single crystalline $\mathrm{Ni}-2 \mathrm{X}$ alloys $(\mathrm{X}=\mathrm{Mo}$, $\mathrm{Re}, \mathrm{Ta}$, and $\mathrm{W})$ were investigated via creep experiments at $1000^{\circ} \mathrm{C}, 1050{ }^{\circ} \mathrm{C}$, and $1100^{\circ} \mathrm{C}$ and $20 \mathrm{MPa}$ to investigate the solid solution hardening behavior of the solutes in a high-temperature low-stress regime. At all three investigated temperatures, the measured creep strength was the highest for Ni-2Re, followed by Ni-2W, and lastly Ni-2Mo and Ni-2Ta with quite comparable creep strength.

The strain rate at $2 \%$ plastic strain, as a substitute for the minimum creep rate, could be linearly correlated to the diffusion, which indicates a direct dependency of the creep strength from the diffusion coefficient of a solute alloying element in binary $\mathrm{Ni}$ alloys in the investigated high-temperature low-stress regime. Together with literature, it could be confirmed that at these high temperatures above $1000^{\circ} \mathrm{C}$, the rate of deformation plays a very important role for the evaluation of the solid solution hardening potential of a solute alloying element due to the increasing influence of time dependent processes, such as diffusion. 
Author Contributions: Conceptualization, S.N., M.G., D.M. and H.u.R.; methodology, S.N. and H.u.R.; formal analysis, S.N., L.H. and H.u.R.; investigation, L.H. and H.u.R.; resources, M.G.; writing—original draft preparation, L.H.; writing—review and editing, L.H., S.N, D.M. and M.G.; visualization, L.H.; supervision, S.N. and M.G.; project administration, M.G.; funding acquisition, M.G. All authors have read and agreed to the published version of the manuscript.

Funding: The authors acknowledge funding by the Deutsche Forschungsgemeinschaft (DFG) through projects A6 and Z01 of the collaborative research center SFB/TR 103 "From Atoms to Turbine Blades-a Scientific Approach for Developing the Next Generation of Single Crystal Superalloys."

Institutional Review Board Statement: Not applicable.

Informed Consent Statement: Not applicable.

Data Availability Statement: The research data are available from the corresponding author on reasonable request.

Acknowledgments: The authors are grateful to Oliver Horst from the Ruhr-Universität Bochum for orienting the single crystals and for the creep specimen manufacturing.

Conflicts of Interest: The authors declare no conflict of interest.

\section{References}

1. Reed, R.C. The Superalloys: Fundamentals and Applications; Cambridge University Press: Cambridge, UK; New York, NY, USA, 2006; ISBN 9780511246869.

2. Kassner, M.E.; Pérez-Prado, M.-T. Fundamentals of Creep in Metals and Alloys; Elsevier: Amsterdam, The Netherlands, 2004; ISBN 978-0-08-043637-1.

3. Ur Rehman, H.; Durst, K.; Neumeier, S.; Sato, A.; Reed, R.; Göken, M. On the Temperature Dependent Strengthening of Nickel by Transition Metal Solutes. Acta Mater. 2017, 137, 54-63. [CrossRef]

4. Zhu, Z.; Basoalto, H.; Warnken, N.; Reed, R.C. A Model for the Creep Deformation Behaviour of Nickel-Based Single Crystal Superalloys. Acta Mater. 2012, 60, 4888-4900. [CrossRef]

5. Epishin, A.I.; Fedelich, B.; Viguier, B.; Schriever, S.; Svetlov, I.L.; Petrushin, N.V.; Saillard, R.; Proietti, A.; Poquillon, D.; Chyrkin, A. Creep of Single-Crystals of Nickel-Base $\gamma$-Alloy at Temperatures between $1150{ }^{\circ} \mathrm{C}$ and $1288^{\circ} \mathrm{C}$. Mater. Sci. Eng. A 2021, 825,141880 . [CrossRef]

6. Lu, F.; Li, L.; Antonov, S.; Zheng, Y.; Fraser, H.L.; Wang, D.; Zhang, J.; Feng, Q. Effect of Re on Long-Term Creep Behavior of Nickel-Based Single-Crystal Superalloys for Industrial Gas Turbine Applications. In Superalloys 2020; Tin, S., Hardy, M., Clews, J., Cormier, J., Feng, Q., Marcin, J., O’Brien, C., Suzuki, A., Eds.; The Minerals, Metals \& Materials Series; Springer International Publishing: Cham, Switzerland, 2020; pp. 218-227. ISBN 978-3-030-51833-2.

7. Fleischmann, E.; Miller, M.K.; Affeldt, E.; Glatzel, U. Quantitative Experimental Determination of the Solid Solution Hardening Potential of Rhenium, Tungsten and Molybdenum in Single-Crystal Nickel-Based Superalloys. Acta Mater. 2015, 87, 350-356. [CrossRef]

8. Latief, F.H.; Kakehi, K. Effects of Re Content and Crystallographic Orientation on Creep Behavior of Aluminized Ni-Base Single Crystal Superalloys. Mater. Des. 2013, 49, 485-492. [CrossRef]

9. Tian, S.; Su, Y.; Qian, B.; Yu, X.; Liang, F.; Li, A. Creep Behavior of a Single Crystal Nickel-Based Superalloy Containing 4.2\% Re. Mater. Des. 2012, 37, 236-242. [CrossRef]

10. Reed, R.C.; Matan, N.; Cox, D.C.; Rist, M.A.; Rae, C.M.F. Creep of CMSX-4 Superalloy Single Crystals: Effects of Rafting at High Temperature. Acta Mater. 1999, 47, 3367-3381. [CrossRef]

11. Glatzel, U.; Schleifer, F.; Gadelmeier, C.; Krieg, F.; Müller, M.; Mosbacher, M.; Völkl, R. Quantification of Solid Solution Strengthening and Internal Stresses through Creep Testing of Ni-Containing Single Crystals at $980{ }^{\circ} \mathrm{C}$. Metals 2021, 11, 1130. [CrossRef]

12. Ru, Y.; Zhang, H.; Pei, Y.; Li, S.; Gong, S. Substituting Mo for Re in Equal Weight for Ni Based Single Crystal Superalloy. Materialia 2019, 6, 100278. [CrossRef]

13. Gaag, T.; Ritter, N.; Peters, A.; Volz, N.; Gruber, D.; Neumeier, S.; Zenk, C.; Körner, C. Improving the Effectiveness of the Solid-Solution-Strengthening Elements Mo, Re, Ru and W in Single-Crystalline Nickel-Based Superalloys. Metals 2021, 11, 1707. [CrossRef]

14. Wu, X.; Makineni, S.K.; Liebscher, C.H.; Dehm, G.; Rezaei Mianroodi, J.; Shanthraj, P.; Svendsen, B.; Bürger, D.; Eggeler, G.; Raabe, D.; et al. Unveiling the Re Effect in Ni-Based Single Crystal Superalloys. Nat. Commun. 2020, 11, 389. [CrossRef]

15. Mishima, Y.; Ochiai, S.; Hamao, N.; Yodogawa, M.; Suzuki, T. Solid Solution Hardening of Nickel-Role of Transition Metal and B-Subgroup Solutes. Trans. Jpn. Inst. Met. 1986, 27, 656-664. [CrossRef]

16. Pelloux, R.; Grant, N.J. Solid Solution and Second Phase Strengthening of Nickel Alloys at High and Low Temperatures. Trans. Metall. Soc. AIME 1959, 218, 232-237. 
17. Wang, M.-X.; Zhu, H.; Yang, G.-J.; Liu, K.; Li, J.-F.; Kong, L.-T. Solid-Solution Strengthening Effects in Binary Ni-Based Alloys Evaluated by High-Throughput Calculations. Mater. Des. 2021, 198, 109359. [CrossRef]

18. Fleischer, R.L. Substitutional Solution Hardening. Acta Metall. 1963, 11, 203-209. [CrossRef]

19. Labusch, R. A Statistical Theory of Solid Solution Hardening. Phys. Status Solidi B 1970, 41, 659-669. [CrossRef]

20. Roth, H.A.; Davis, C.L.; Thomson, R.C. Modeling Solid Solution Strengthening in Nickel Alloys. Metall. Mater. Trans. A 1997, 28, 1329-1335. [CrossRef]

21. Diologent, F.; Caron, P. On the Creep Behavior at $1033 \mathrm{~K}$ of New Generation Single-Crystal Superalloys. Mater. Sci. Eng. A 2004, 385, 245-257. [CrossRef]

22. Hirth, J.P.; Lothe, J. Theory of Dislocations, 2nd ed.; Wiley: New York, NY, USA, 1982; ISBN 978-0-471-09125-7.

23. Bürgel, R.; Maier, H.J.; Niendorf, T. Handbuch Hochtemperatur-Werkstofftechnik: Grundlagen, Werkstoffbeanspruchungen, Hochtemperaturlegierungen Und-Beschichtungen; Vieweg + Teubner: Wiesbaden, Germany, 2011; ISBN 978-3-8348-1388-6.

24. Karunaratne, M.S.A.; Carter, P.; Reed, R.C. Interdiffusion in the Face-Centred Cubic Phase of the Ni-Re, Ni-Ta and Ni-W Systems between 900 and $1300{ }^{\circ}$ C. Mater. Sci. Eng. A 2000, 281, 229-233. [CrossRef]

25. Karunaratne, M.S.A.; Reed, R.C. Interdiffusion of Niobium and Molybdenum in Nickel between $900-1300{ }^{\circ}$ C. Defect Diffus. Forum 2005, 237-240, 420-425. [CrossRef]

26. Rettig, R.; Ritter, N.C.; Helmer, H.E.; Neumeier, S.; Singer, R.F. Single-Crystal Nickel-Based Superalloys Developed by Numerical Multi-Criteria Optimization Techniques: Design Based on Thermodynamic Calculations and Experimental Validation. Model. Simul. Mater. Sci. Eng. 2015, 23, 035004. [CrossRef]

27. Giese, S.; Bezold, A.; Pröbstle, M.; Heckl, A.; Neumeier, S.; Göken, M. The Importance of Diffusivity and Partitioning Behavior of Solid Solution Strengthening Elements for the High Temperature Creep Strength of Ni-Base Superalloys. Metall. Mater. Trans. A 2020, 51, 6195-6206. [CrossRef]

28. Sato, A.; Moverare, J.J.; Hasselqvist, M.; Reed, R.C. On the Mechanical Behavior of a New Single-Crystal Superalloy for Industrial Gas Turbine Applications. Metall. Mater. Trans. A 2012, 43, 2302-2315. [CrossRef]

29. Mohamed, F.A. Creep Behavior of Solid Solution Alloys. Mater. Sci. Eng. 1979, 38, 73-80. [CrossRef]

30. Mohamed, F.A.; Langdon, T.G. The Transition from Dislocation Climb to Viscous Glide in Creep of Solid Solution Alloys. Acta Metall. 1974, 22, 779-788. [CrossRef] 